\title{
Review Article \\ Influence of Grain Size and Texture on the Yield Strength of Mg Alloys Processed by Severe Plastic Deformation
}

\author{
Jinbao Lin, ${ }^{1,2}$ Weijie Ren, ${ }^{1}$ Qudong Wang, ${ }^{3}$ Lifeng Ma, ${ }^{2}$ and Yongjun Chen ${ }^{4}$ \\ ${ }^{1}$ School of Applied Science, Taiyuan University of Science and Technology, Wanbailin District, Taiyuan 030024, China \\ ${ }^{2}$ Center of Rolling Engineering, Taiyuan University of Science and Technology, Taiyuan 030024, China \\ ${ }^{3}$ National Engineering Research Center for Light Alloy Net Forming, Shanghai Jiao Tong University, Shanghai 200240, China \\ ${ }^{4}$ ERC of Revolutionizing Metallic Biomaterials, North Carolina A\&T State University, Greensboro, NC 27411, USA
}

Correspondence should be addressed to Jinbao Lin; linjinbao@qq.com

Received 26 July 2014; Revised 1 November 2014; Accepted 5 November 2014; Published 25 November 2014

Academic Editor: Tao Zhang

Copyright (C) 2014 Jinbao Lin et al. This is an open access article distributed under the Creative Commons Attribution License, which permits unrestricted use, distribution, and reproduction in any medium, provided the original work is properly cited.

\begin{abstract}
Severe plastic deformation (SPD) has been widely employed to refine the grain size of $\mathrm{Mg}$ alloys, with the main objective to improve the strength and ductility of Mg alloys, since the well-known Hall-Petch equation suggests that a decreased grain size leads to an increased yield strength. However, the yield strength of Mg alloys processed by SPD is often decreased even though the grain size is effectively reduced. The abnormal flow behavior in Mg alloys processed by SPD has attracted great attention although this mechanism is still unclear, due to its complex and extensive influence factors. In this paper, the relationships between the processing conditions, grain refinement, and mechanical properties of the SPD treated Mg alloys are reviewed, with the emphasis on the effects of grain size and texture on the yield strength.
\end{abstract}

\section{Introduction}

The use of magnesium alloys in industrial fields, such as the automotive and bicycle industries, has gained much attention due to their energy-efficient properties which include low density and high specific strength. However, the application of magnesium alloy is greatly limited for its relatively low strength and plasticity. An effective way to improve the mechanical properties of magnesium alloy is to refine the grains $[1,2]$. For the polycrystalline materials, the yield stress $\sigma_{y}$ varies with average grain size $d$ according to Hall-Petch relationship $\left(\sigma_{y}=\sigma_{0}+k_{y} \cdot d^{-1 / 2}\right.$, where $\sigma_{0}$ is a friction stress required to move dislocations and $k_{y}$ is the stress concentration factor). At room temperature, the Hall-Petch slope $k_{y}$ value for pure magnesium is quite higher than that of pure aluminum, so it is much more effective to enhance the strength of $\mathrm{Mg}$ alloys by simply refining the grain size [3].

Severe plastic deformation (SPD) has been a widely used method to fabricate ultrafine grained metals and alloys, by introducing an ultralarge plastic strain into a bulk metal without any significant change in the overall dimensions
$[4,5]$. Among the various SPD techniques, equal channel angular pressing (ECAP) and cyclic extrusion and compression (CEC) are attractive due to their characteristics of processing the relatively large bulk samples [5-9]. Up to now, ECAP processing has received the most attention from researchers than other SPD processes, including CEC. However, CEC seems to be more promising for industrial applications due to its continuous process. Moreover, it is very suitable for refining grains of hard-to-deform metals, for example, magnesium alloys, since it imposes threedimensional compression stresses during processing [10].

It has been widely proved that the microstructures of $\mathrm{Mg}$ alloys can be dramatically refined by the ECAP and CEC processes [1, 2, 6, 10-14]. Nevertheless, the ECAP and CEC processed $\mathrm{Mg}$ alloys often showed a decreased yield strength even though grain size is effectively reduced, and this abnormal result has been attributed to the effect of the texture that developed during ECAP and CEC processing $[6,15-23]$. However, researchers still report an increase in yield strength of fine-grained $\mathrm{Mg}$ alloys processed by ECAP and CEC [13, 24-32]. These discrepancies indicate that the effects of ECAP 


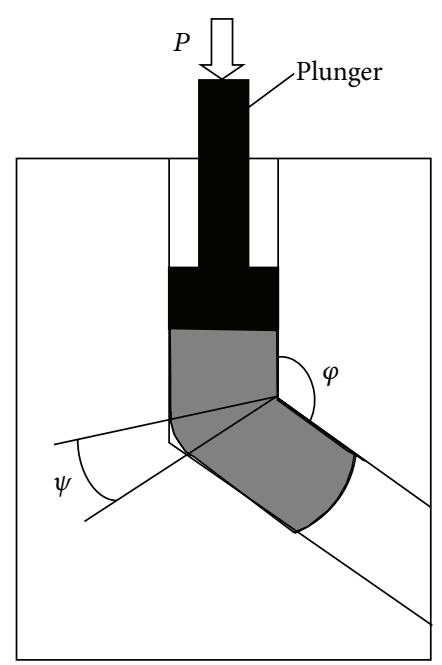

FIgURE 1: Schematic illustration of the ECAP process [33].

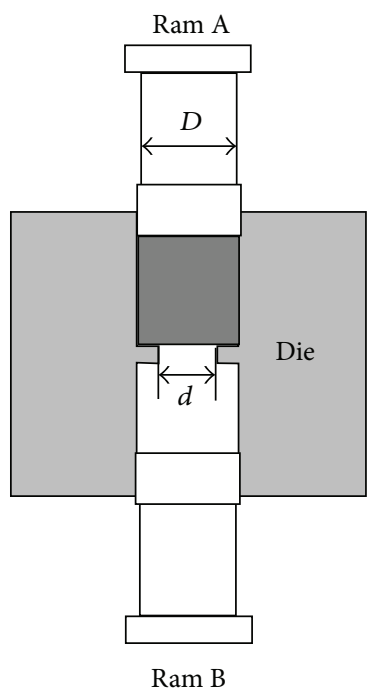

(a)

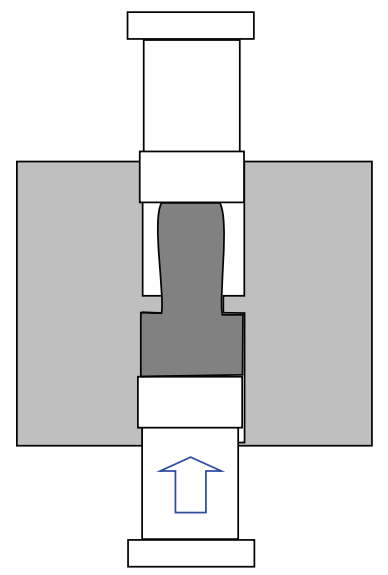

(d)

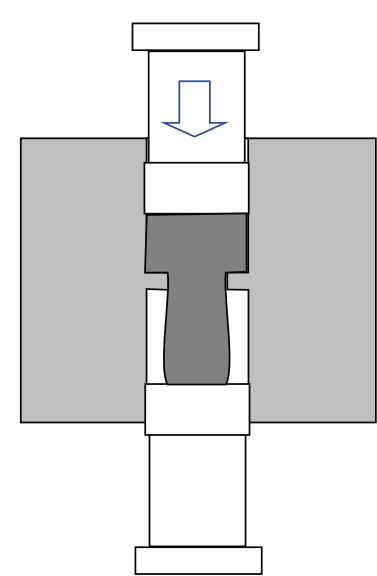

(b)

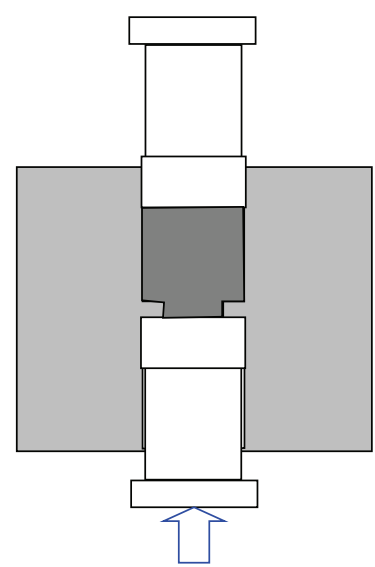

(e)

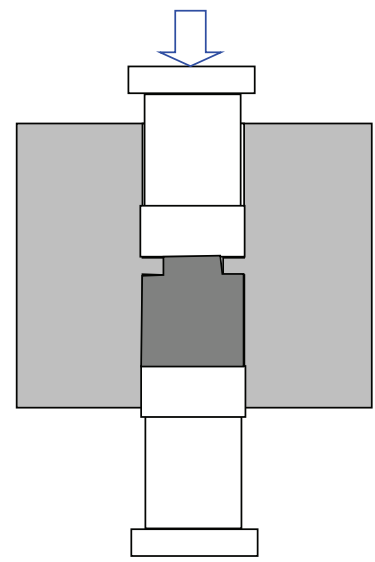

(c)

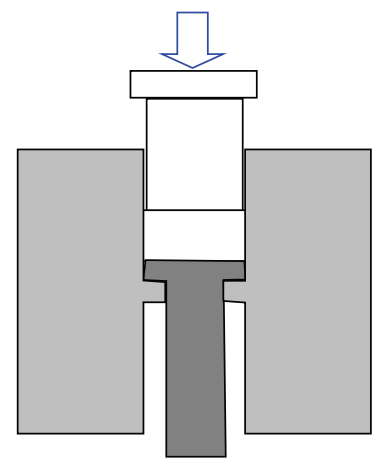

(f)

FIGURE 2: Schematic illustration of the CEC facility and procedures: (a) initial state, (b) extruding by Ram A, (c) end of Ram A involvement, (d) reverse extruding employing Ram B, (e) end of Ram B involvement, and (f) final extrusion to obtain a rod [6]. 


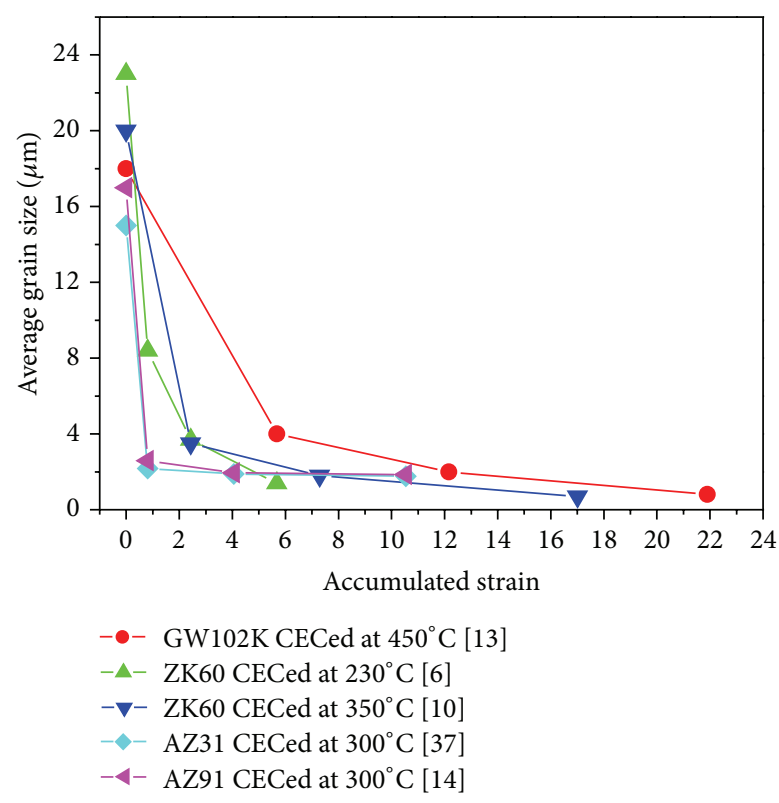

(a)

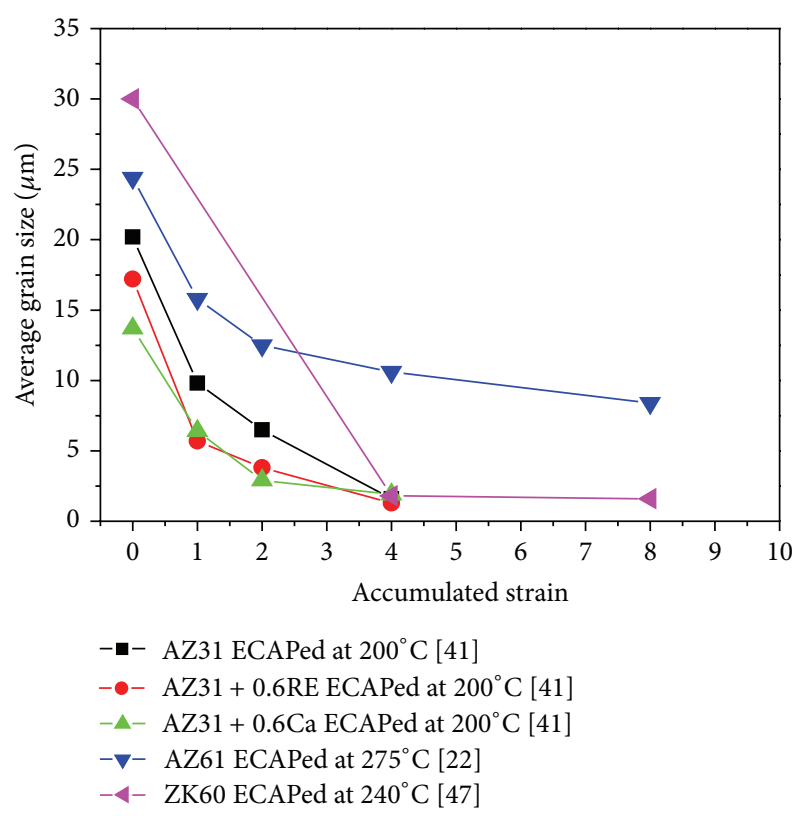

(b)

FIGURE 3: Grain size of Mg alloys as a function of the accumulated strains of (a) CEC and (b) ECAP.

and CEC processes on the mechanical properties of $\mathrm{Mg}$ alloy are complicated. In this paper, the relationships among the processing conditions, grain refinement, and mechanical properties of the $\mathrm{Mg}$ alloys processed by ECAP and CEC are discussed, with the emphasis on the effects of grain size and texture on the yield strength.

\section{The Principle of ECAP and CEC}

The process of ECAP was first introduced by Segal and his coworkers in the 1970s and 1980s [40]. Figure 1 shows a schematic illustration of a section through the ECAP facility [33], with the die consisting of two channels, equal in crosssection. The ECAP is conducted by pressing the sample through the die using a plunger. The strain accumulated in ECAP is given by the expression [41]

$$
\varepsilon_{N}=\frac{N}{\sqrt{3}}\left[2 \cot \left(\frac{\varphi}{2}+\frac{\psi}{2}\right)+\psi \operatorname{cosec}\left(\frac{\varphi}{2}+\frac{\psi}{2}\right)\right]
$$

where $N$ is the number of passes through the die, $\phi$ is the angle of intersection of two channels, and $\psi$ is the angle subtended by the arc of curvature at the outer point of intersection. When $\phi=90^{\circ}$ and $\psi=0^{\circ}$, the strain of $\sim 1$ is introduced into the sample in each pass through the die.

The CEC processing was proposed by Richert et al. [42], which is performed by pushing a sample from one cylindrical chamber with a diameter $D$ into the second chamber with the same dimensions, through a die having a smaller diameter $d$, as illustrated in Figure 2 [6]. This will form one "cycle" of the CEC process. During the final extrusion cycle, the opposite ram is removed in order to release the rod. The equivalent strain $\varepsilon$ generated in the specimen after $N$ cycles of CEC processing is given by the following equation $[10,42]$ :

$$
\varepsilon=2 N \ln \frac{D^{2}}{d^{2}}-\ln \frac{D^{2}}{d^{2}}=2(2 N-1) \ln \frac{D}{d} .
$$

\section{Microstructures of ECAP and CEC Processed Mg Alloys}

3.1. Grain Refinement. Figure 3 shows the grain refinement of $\mathrm{Mg}$ alloys processed by ECAP $[22,38,43]$ and CEC $[6,10$, $13,14,37]$. The average grain sizes were measured primarily by the linear intercept method. It can be seen that both the ECAP and CEC are efficient grain refinement methods for $\mathrm{Mg}$ alloys. Grain refinement takes place mainly during early stage of ECAP and CEC, and the grain size decreases slowly with further increasing strain till a balance occurs between the grain refinement and grain growth. Compared with the ECAP processed (ECAPed) Mg alloys, the CEC processed (CECed) Mg alloys exhibit a finer grain size, under the similar deformation conditions of accumulated strain and temperature. This may be due to the CEC processing which introduces a large hydrostatic compressive stress into the alloy [10]. In addition, the finer microstructures can be achieved by a lower deformation temperature.

Table 1 summarizes the data on grain refinement and yield strength for Mg alloys after ECAP and CEC processing. It can be seen that ultrafine grained $\mathrm{Mg}$ alloys with the grain size below $1 \mu \mathrm{m}$ can be produced by ECAP and CEC processing. Moreover, the finer the initial grain size is, the finer the final grain size will be. However, even though the grain size is reduced effectively, some CECed $[6,10,37]$ and ECAPed $[18,21,22,29,34-36,38] \mathrm{Mg}$ alloys showed a decreased yield 


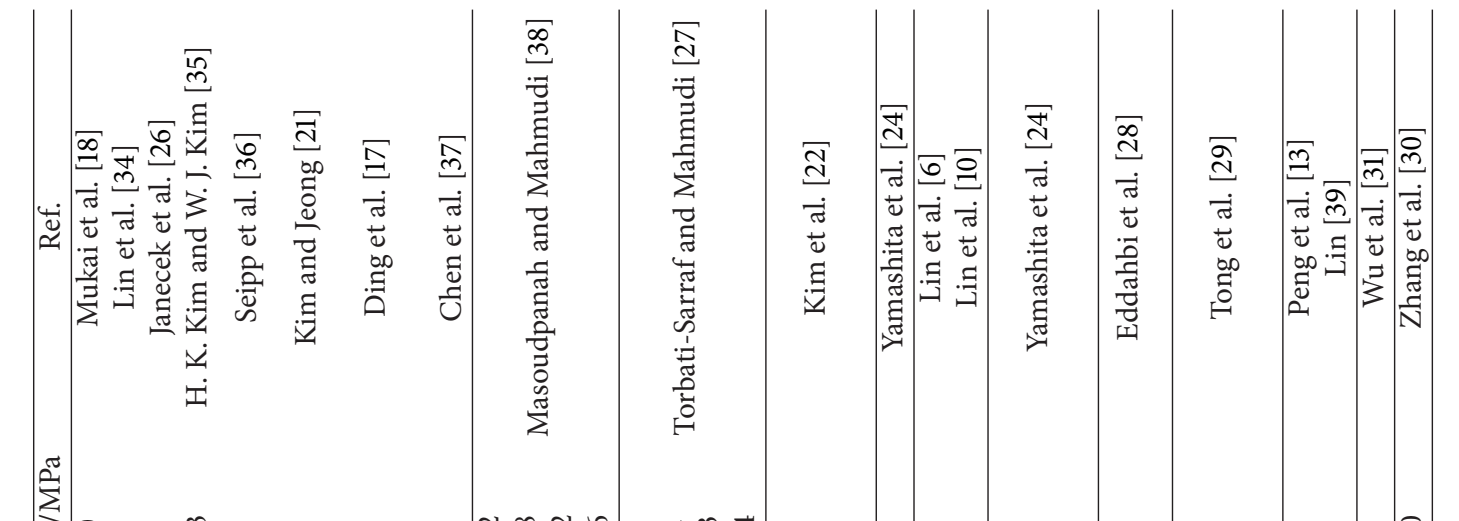

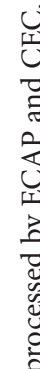
s.

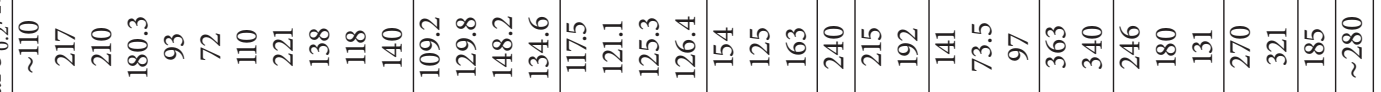




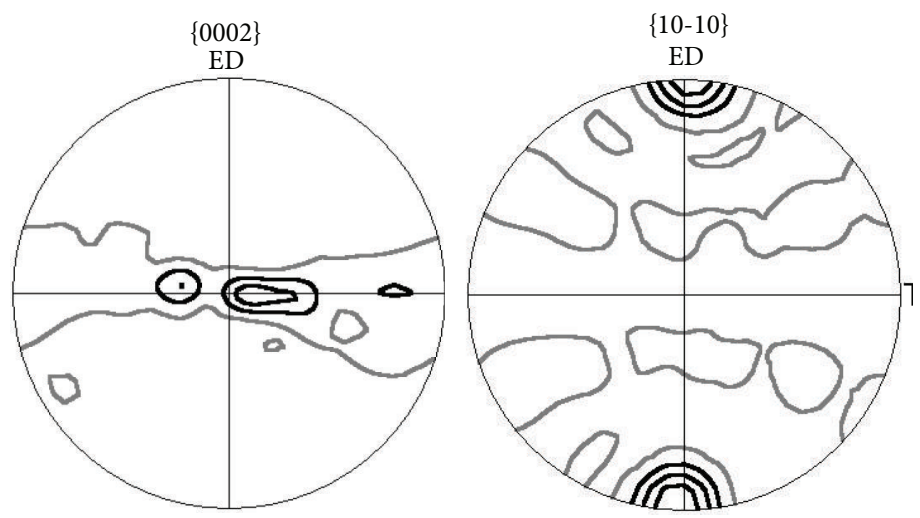

(a)
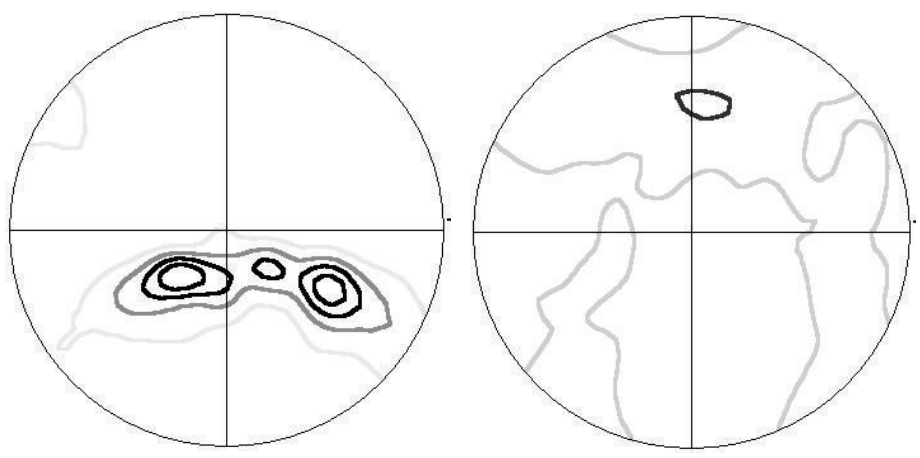

(b)
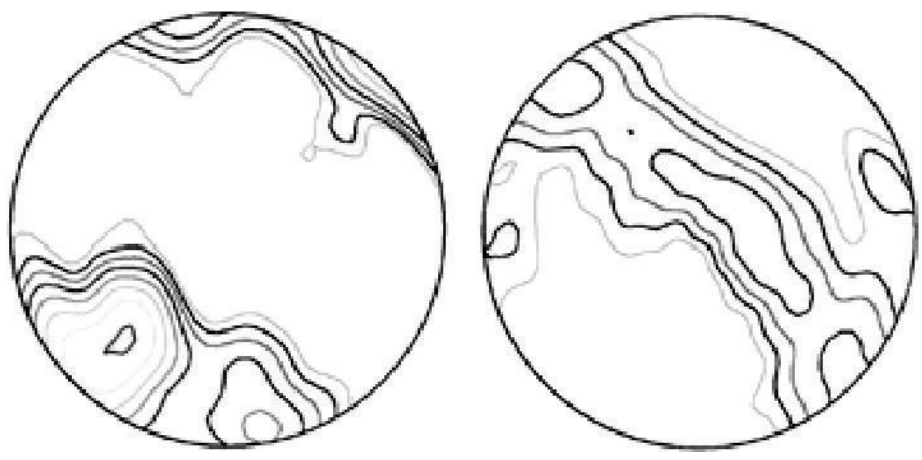

(c)

FIGURE 4: Typical $\{0002\}$ and $\{10-10\}$ pole figures of Mg alloys processed by (a) conventional extrusion [9], (b) CEC [9], and (c) ECAP (route $\left.B_{c}\right)$ [17].

strength. On the other hand, the other references in Table 1 report an increase in the yield strength. These abnormal results have been attributed to the combined effect of the texture modification and grain refinement caused by ECAP and CEC processing, but the mechanism is still under debate due to the complex and extensive influence factors.

3.2. Texture Evolution. For $\mathrm{Mg}$ alloys, a strong texture is always present after forming due to its HCP structure with limited nonbasal slip activities. Different textures are expected to result from different processing routes with different strain paths. Figure 4 shows the typical $\{0002\}$ and \{10-10\} pole figures of conventional extruded ZK60 alloy [9], 4-cycle CECed ZK60 alloy [9], and 4-pass ECAPed AZ31 alloy (route $B_{c}$ ) [17], and Figure 5 shows the schematic illustration of the dominant texture in the extruded CEC and ECAP conditions. It has been reported that the deformation texture type of $\mathrm{Mg}$ alloys is mainly determined by the characteristics of the plastic deformation process [44]. The extruded Mg alloys always exhibit an ED// $\langle 10-10\rangle$ fiber texture, in which the $\{0002\}$ basal plane is parallel to the extrusion direction $[6,10]$. After CEC and ECAP deformation, the basal planes are mainly inclined about $\sim 30^{\circ}[10]$ and $\sim 45^{\circ}[17,45]$ to the extrusion axis, respectively, which are more favorable conditions for basal slip activity and resulting in a decrease in the yield strength. 


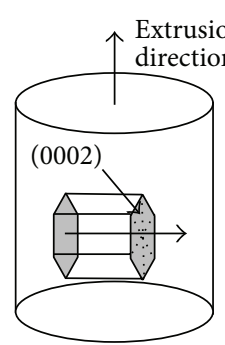

Extruded

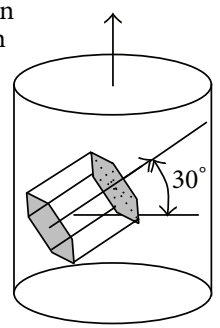

CEC

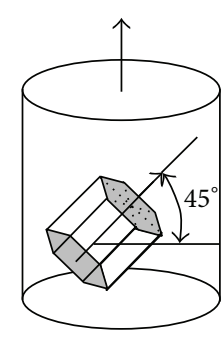

ECAP

FIGURE 5: Schematic showing the dominant texture in the extruded ECAP and CEC conditions.

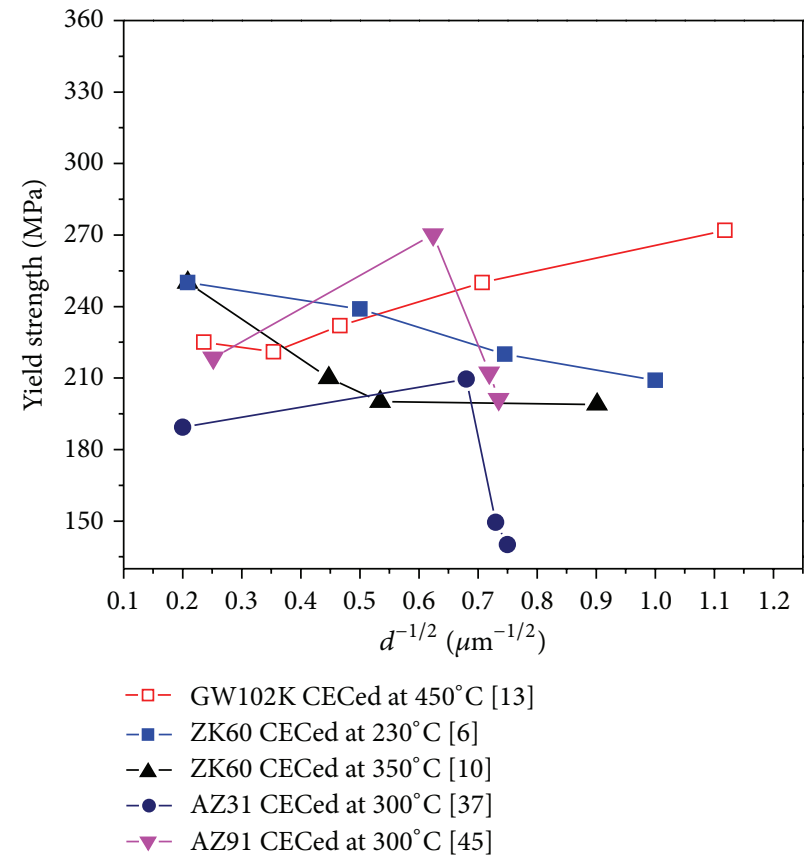

(a)

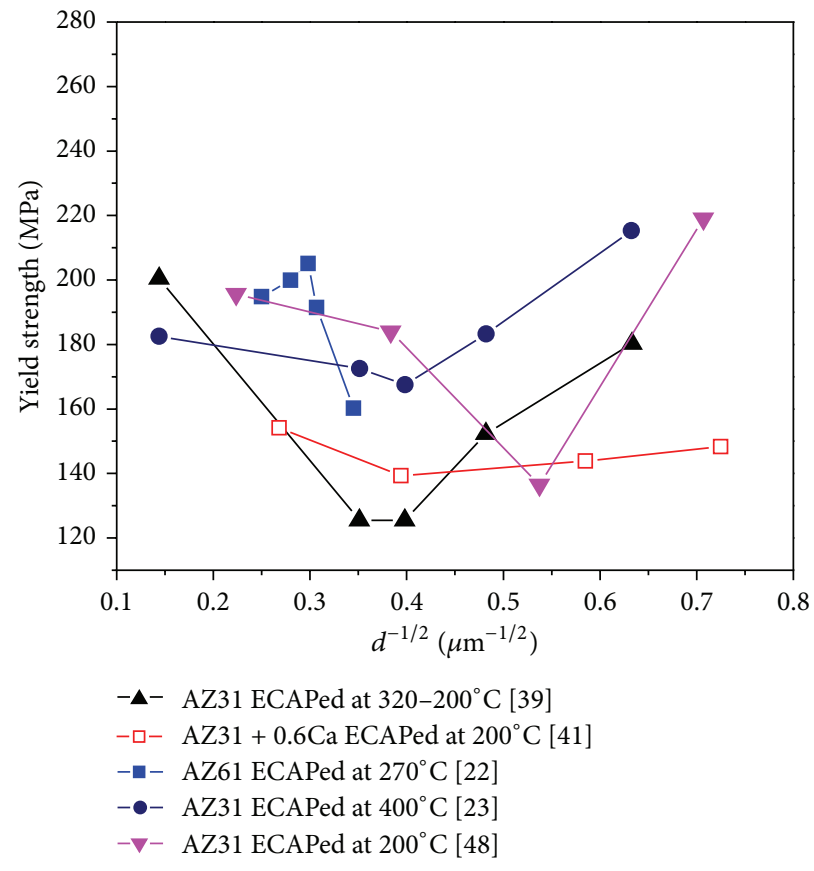

(b)

FIGURE 6: Grain size dependencies of yield strength of Mg alloys processed by (a) CEC and (b) ECAP.

\section{Yield Strength of the ECAP and CEC Processed Mg Alloys}

Figure 6 shows the grain size dependencies of yield strength of $\mathrm{Mg}$ alloys processed by CEC $[6,10,13,37,46]$ and ECAP $[22,23,35,38,47]$. It can be seen that almost all ECAPed and CECed $\mathrm{Mg}$ alloys exhibit a decrease in yield strength, especially in the early stage of ECAP and CEC deformation. With further decrease in the grain size, the yield strength starts to increase. The abnormal decrease in yield strength of the SPD refined Mg alloys has been attributed to the modification of the texture. It is known that the grains of as-extruded $\mathrm{Mg}$ alloy in a "hard" orientation with low Schmid factor, that is, the basal plane slip, are difficult to be activated. After ECAP and CEC, the grains orientations are more favorable for basal slip activity and resulting in a decrease in the yield strength. It is understood that the texture softening, caused by texture change, overwhelms the strengthening due to grain refinement at the early stage of ECAP and CEC deformation.
With further increase in deformation strain, grain refinement strengthening overwhelms the texture softening, and then the yield strength starts to increase.

Additionally, as shown in Figure 6(a), even though having a similar texture type with other CECed Mg alloys, the CECed GW102K alloy exhibits a monotonically increasing yield strength. The opposite relationships between grain size and yield strength of the CECed Mg alloys can be ascribed to the different texture intensity. Peng et al. [13] showed that the texture intensity of the CECed GW102K alloy is much lower than that of the CECed ZK60 alloy.

It has been reported that the annealing treatment produces almost no change on the texture of the ECAPed $\mathrm{Mg}$ alloy $[16,21,46,48]$. So, the SPD processed (SPDed) $\mathrm{Mg}$ alloys with different grain sizes but with similar texture can be prepared by the SPD process and post-SPD annealing. In Figure 7 , the yield stress is plotted against $d^{-1 / 2}$ for the SPD + annealed Mg alloys, based on the Hall-Petch relationship, to examine the grain size effect on the SPDed 


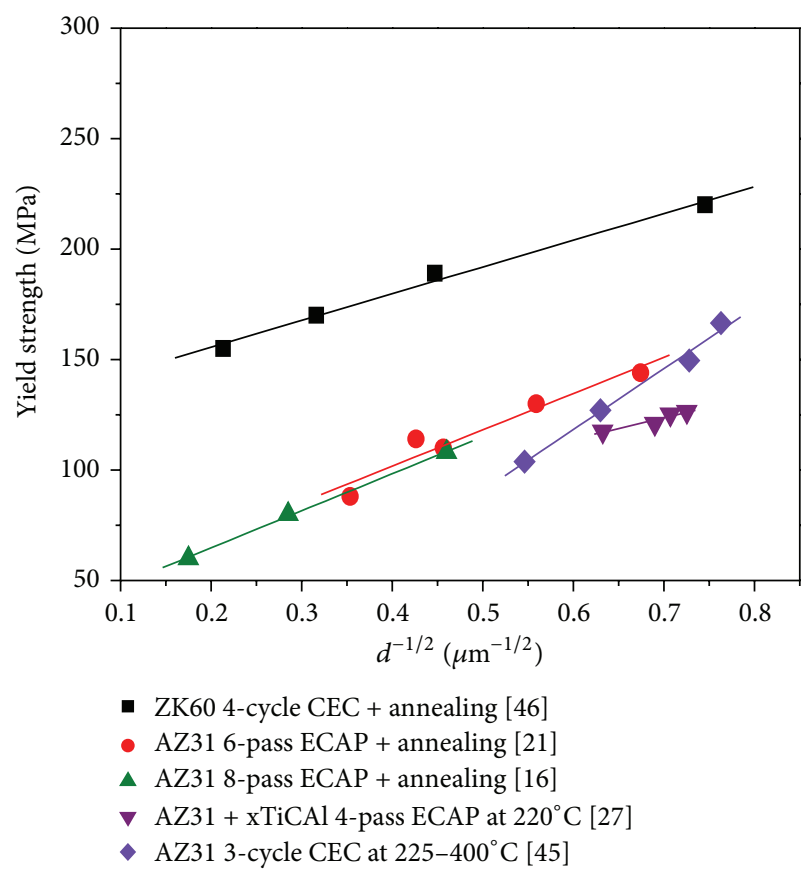

FIGURE 7: Grain size dependencies of yield strength of Mg alloy after SPD process and annealing.

Mg alloys. It can be seen that the strength of the SPDed $\mathrm{Mg}$ alloys increases with the decrease of grain size, which is in agreement with the standard Hall-Petch relationship (a positive slope in the plot of yield stress versus $d^{-1 / 2}$ ). The standard positive strength dependence on the grain size for Mg alloys, with the similar texture, supports that the softening of SPDed Mg alloys (a negative slope) which are typically observed despite the significant grain refinement, is due to the texture modification where the rotation of basal planes occurs towards the orientation for easier slip [21]. Thus, it can be concluded that the yield strength of the SPDed Mg alloy is determined by the competition of grain size strengthening effect and texture softening effect, and the texture softening depends on the texture type and texture intensity.

\section{Summary and Conclusions}

(1) Both the ECAP and CEC are efficient grain refinement methods for $\mathrm{Mg}$ alloys, and grain refinement takes place mainly during early stage of ECAP and CEC. Compared with the ECAPed Mg alloys, the CECed Mg alloys exhibit a finer grain size, under similar deformation conditions of accumulated strain and temperature.

(2) The yield strength of ECAPed and CECed Mg alloys is determined by the competition of grain size strengthening effect and texture softening effect, and the texture softening depends on the texture type and texture intensity.

(3) A standard positive Hall-Petch relation can be obtained in the ECAPed and CECed alloys when texture is constant.

\section{Conflict of Interests}

The authors declare that there is no conflict of interests regarding the publication of this paper.

\section{Acknowledgments}

This work is financially supported by the National Natural Science Foundation of China (Grants nos. 51204117 and 51074106), the Natural Science Foundation of Shanxi (Grant no. 2012021018-2), and the Program for the Top Young Academic Leaders of Higher Learning Institutions of Shanxi.

\section{References}

[1] Y. Miyahara, Z. Horita, and T. G. Langdon, "Exceptional superplasticity in an AZ61 magnesium alloy processed by extrusion and ECAP," Materials Science and Engineering A, vol. 420, no. 1-2, pp. 240-244, 2006.

[2] M. R. Barnett, Z. Keshavarz, A. G. Beer, and D. Atwell, "Influence of grain size on the compressive deformation of wrought Mg-3Al-1Zn," Acta Materialia, vol. 52, no. 17, pp. 5093-5103, 2004.

[3] M. H. Yoo, "Slip, twinning, and fracture in hexagonal closepacked metals," Metallurgical Transactions A, vol. 12, no. 3, pp. 409-418, 1981.

[4] R. Z. Valiev, Y. Estrin, Z. Horita, T. G. Langdon, M. J. Zehetbauer, and Y. T. Zhu, "Producing bulk ultrafine-grained materials by severe plastic deformation," JOM, vol. 58, no. 4, pp. 33-39, 2006.

[5] Y. Estrin and A. Vinogradov, "Extreme grain refinement by severe plastic deformation: a wealth of challenging science," Acta Materialia, vol. 61, no. 3, pp. 782-817, 2013.

[6] J. Lin, Q. Wang, L. Peng, and H. J. Roven, "Microstructure and high tensile ductility of ZK60 magnesium alloy processed by cyclic extrusion and compression," Journal of Alloys and Compounds, vol. 476, no. 1-2, pp. 441-445, 2009.

[7] J. F. Jiang, Y. Wang, and J. J. Qu, "Microstructure and mechanical properties of AZ61 alloys with large cross-sectional size fabricated by multi-pass ECAP," Materials Science and Engineering: $A$, vol. 560, pp. 473-480, 2013.

[8] J.-B. Lin, Q.-D. Wang, M.-P. Liu, Y.-J. Chen, and H. J. Roven, "Finite element analysis of strain distribution in ZK60 Mg alloy during cyclic extrusion and compression," Transactions of Nonferrous Metals Society of China, vol. 22, no. 8, pp. 1902-1906, 2012.

[9] J. B. Lin, Q. D. Wang, Y. J. Chen, M. P. Liu, and H. J. Roven, "Microstructure and texture characteristics of ZK60 Mg alloy processed by cyclic extrusion and compression," Transactions of Nonferrous Metals Society of China, vol. 20, no. 11, pp. 20812085, 2010.

[10] J. Lin, Q. Wang, L. Peng, and T. Peng, "Effect of the cyclic extrusion and compression processing on microstructure and mechanical properties of as-extruded ZK60 magnesium alloy," Materials Transactions, vol. 49, no. 5, pp. 1021-1024, 2008.

[11] S. M. Masoudpanah and R. Mahmudi, "Effects of rare earth elements and $\mathrm{Ca}$ additions on high temperature mechanical properties of AZ31 magnesium alloy processed by ECAP," Materials Science and Engineering A, vol. 527, no. 16-17, pp. 3685-3689, 2010. 
[12] R. B. Figueiredo and T. G. Langdon, "Grain refinement and mechanical behavior of a magnesium alloy processed by ECAP," Journal of Materials Science, vol. 45, no. 17, pp. 4827-4836, 2010.

[13] T. Peng, Q. Wang, J. Lin, M. Liu, and H. J. Roven, "Microstructure and enhanced mechanical properties of an Mg-10Gd-2Y$0.5 \mathrm{Zr}$ alloy processed by cyclic extrusion and compression," Materials Science and Engineering: A, vol. 528, no. 3, pp. 11431148, 2011.

[14] Q. Wang, Y. Chen, M. Liu, J. Lin, and H. J. Roven, "Microstructure evolution of AZ series magnesium alloys during cyclic extrusion compression," Materials Science and Engineering A, vol. 527, no. 9, pp. 2265-2273, 2010.

[15] S. Suwas, G. Gottstein, and R. Kumara, "Evolution of crystallographic texture during equal channel angular extrusion (ECAE) and its effects on secondary processing of magnesium," Materials Science and Engineering: A, vol. 471, no. 1-2, pp. 1-14, 2007.

[16] Y. Yoshida, L. Cisar, S. Kamado, and Y. Kojima, "Effect of microstructural factors on tensile properties of an ECAEprocessed AZ31 magnesium alloy," Materials Transactions, vol. 44, no. 4, pp. 468-475, 2003.

[17] S. X. Ding, W. T. Lee, C. P. Chang, L. W. Chang, and P. W. Kao, "Improvement of strength of magnesium alloy processed by equal channel angular extrusion," Scripta Materialia, vol. 59, no. 9, pp. 1006-1009, 2008.

[18] T. Mukai, M. Yamanoi, H. Watanabe, and K. Higashi, "Ductility enhancement in AZ31 magnesium alloy by controlling its grain structure," Scripta Materialia, vol. 45, no. 1, pp. 89-94, 2001.

[19] W. J. Kim, S. J. Yoo, Z. H. Chen, and H. T. Jeong, "Grain size and texture control of $\mathrm{Mg}-3 \mathrm{Al}-1 \mathrm{Zn}$ alloy sheet using a combination of equal-channel angular rolling and high-speedratio differential speed-rolling processes," Scripta Materialia, vol. 60, no. 10, pp. 897-900, 2009.

[20] W. Yuan, S. K. Panigrahi, J. Q. Su, and R. S. Mishra, "Influence of grain size and texture on Hall-Petch relationship for a magnesium alloy," Scripta Materialia, vol. 65, no. 11, pp. 994997, 2011.

[21] W. J. Kim and H. T. Jeong, "Grain-size strengthening in equalchannel-angular-pressing processed AZ31 Mg alloys with a constant texture," Materials Transactions, vol. 46, pp. 251-258, 2005.

[22] W. J. Kim, S. I. Hong, Y. S. Kim, S. H. Min, H. T. Jeong, and J. D. Lee, "Texture development and its effect on mechanical properties of an AZ61 Mg alloy fabricated by equal channel angular pressing," Acta Materialia, vol. 51, no. 11, pp. 3293-3307, 2003.

[23] H. K. Kim, "The grain size dependence of flow stress in an ECAPed AZ31 Mg alloy with a constant texture," Materials Science and Engineering: A, vol. 515, pp. 66-70, 2009.

[24] A. Yamashita, Z. Horita, and T. G. Langdon, "Improving the mechanical properties of magnesium and a magnesium alloy through severe plastic deformation," Materials Science and Engineering: A, vol. 300, no. 1-2, pp. 142-147, 2001.

[25] W. M. Gan, M. Y. Zheng, H. Chang et al., "Microstructure and tensile property of the ECAPed pure magnesium," Journal of Alloys and Compounds, vol. 470, no. 1-2, pp. 256-262, 2009.

[26] M. Janecek, M. Popov, M. G. Krieger, R. J. Hellmig, and Y. Estrin, "Mechanical properties and microstructure of a Mg alloy AZ31 prepared by equal-channel angular pressing," Materials Science and Engineering A, vol. 462, no. 1-2, pp. 116-120, 2007.

[27] S. A. Torbati-Sarraf and R. Mahmudi, "Microstructure and mechanical properties of extruded and ECAPed AZ31 Mg alloy, grain refined with Al-Ti-C master alloy," Materials Science and Engineering A, vol. 527, no. 15, pp. 3515-3520, 2010.

[28] M. Eddahbi, P. Pérez, M. A. Monge, G. Garcés, R. Pareja, and P. Adeva, "Microstructural characterization of an extruded MgNi-Y-RE alloy processed by equal channel angular extrusion," Journal of Alloys and Compounds, vol. 473, no. 1-2, pp. 79-86, 2009.

[29] L. B. Tong, M. Y. Zheng, X. S. Hu et al., "Influence of ECAP routes on microstructure and mechanical properties of $\mathrm{Mg}-\mathrm{Zn}$ Ca alloy," Materials Science and Engineering A, vol. 527, no. 16-17, pp. 4250-4256, 2010.

[30] X. Zhang, G. Yuan, and Z. Wang, "Mechanical properties and biocorrosion resistance of $\mathrm{Mg}-\mathrm{Nd}-\mathrm{Zn}-\mathrm{Zr}$ alloy improved by cyclic extrusion and compression," Materials Letters, vol. 74, pp. 128-131, 2012.

[31] Q. Wu, S. Zhu, L. Q. Liu, G. Yue, J. Wang, and S. Guan, “The microstructure and properties of cyclic extrusion compression treated $\mathrm{Mg}-\mathrm{Zn}-\mathrm{Y}-\mathrm{Nd}$ alloy for vascular stent application," Journal of the Mechanical Behavior of Biomedical Materials, vol. 8, pp. 1-7, 2012.

[32] R. Ding, C. Chung, Y. Chiu, and P. Lyon, "Effect of ECAP on microstructure and mechanical properties of ZE41 magnesium alloy," Materials Science and Engineering A, vol. 527, no. 16-17, pp. 3777-3784, 2010.

[33] A. Azushima, R. Kopp, A. Korhonen et al., "Severe plastic deformation (SPD) processes for metals," CIRP AnnalsManufacturing Technology, vol. 57, no. 2, pp. 716-735, 2008.

[34] H. K. Lin, J. C. Huang, and T. G. Langdon, "Relationship between texture and low temperature superplasticity in an extruded AZ31 Mg alloy processed by ECAP," Materials Science and Engineering: A, vol. 402, no. 1-2, pp. 250-257, 2005.

[35] H. K. Kim and W. J. Kim, "Microstructural instability and strength of an AZ31 Mg alloy after severe plastic deformation," Materials Science and Engineering: A, vol. 385, pp. 300-308, 2004.

[36] S. Seipp, M. F. Wagner, K. Hockauf, I. Schneider, L. W. Meyer, and M. Hockauf, "Microstructure, crystallographic texture and mechanical properties of the magnesium alloy AZ31B after different routes of thermo-mechanical processing," International Journal of Plasticity, vol. 35, pp. 155-166, 2012.

[37] Y. J. Chen, Q. D. Wang, H. J. Roven et al., "Network-shaped finegrained microstructure and high ductility of magnesium alloy fabricated by cyclic extrusion compression," Scripta Materialia, vol. 58, no. 4, pp. 311-314, 2008.

[38] S. M. Masoudpanah and R. Mahmudi, "Effects of rare-earth elements and $\mathrm{Ca}$ additions on the microstructure and mechanical properties of AZ31 magnesium alloy processed by ECAP," Materials Science and Engineering A, vol. 526, no. 1-2, pp. 2230, 2009 .

[39] J. B. Lin, Shanghai JiaoTong University, Shanghai, China, 2009.

[40] V. M. Segal, V. I. Reznikov, A. E. Drobyshevskii, and V. I. Kopylov, "Plastic metal working by simple shear," Izvestia Akademii nauk, no. 1, pp. 115-123, 1981.

[41] Y. Iwahashi, J. Wang, Z. Horita, M. Nemoto, and T. G. Langdon, "Principle of equal-channel angular pressing for the processing of ultra-fine grained materials," Scripta Materialia, vol. 35, no. 2, pp. 143-146, 1996.

[42] M. Richert, Q. Liu, and N. Hansen, "Microstructural evolution over a large strain range in aluminium deformed by cyclicextrusion-compression," Materials Science and Engineering A, vol. 260, no. 1-2, pp. 275-283, 1999. 
[43] Y. He, Q. Pan, Y. Qin, X. Liu, and W. Li, "Microstructure and mechanical properties of ultrafine grain ZK60 alloy processed by equal channel angular pressing," Journal of Materials Science, vol. 45, no. 6, pp. 1655-1662, 2010.

[44] J. Lin, Q. Wang, Y. Chen, and X. Cui, "Influence of grain refinement and texture evolution on the yield strength of $\mathrm{mg}$ alloy processed by cyclic extrusion and compression," Materials Transactions, vol. 55, no. 1, pp. 120-122, 2014.

[45] S. R. Agnew, J. A. Horton, T. M. Lillo, and D. W. Brown, "Enhanced ductility in strongly textured magnesium produced by equal channel angular processing," Scripta Materialia, vol. 50, no. 3, pp. 377-381, 2004.

[46] Y. J. Chen Shanghai JiaoTong University, Shanghai, China, 2008.

[47] K. Xia, J. T. Wang, X. Wu, G. Chen, and M. Gurvan, "Equal channel angular pressing of magnesium alloy AZ31," Materials Science and Engineering A, vol. 410-411, pp. 324-327, 2005.

[48] Y. Yoshida, K. Arai, S. Itoh, S. Kamado, and Y. Kojima, "Realization of high strength and high ductility for AZ61 magnesium alloy by severe warm working," Science and Technology of Advanced Materials, vol. 6, no. 2, pp. 185-194, 2005. 

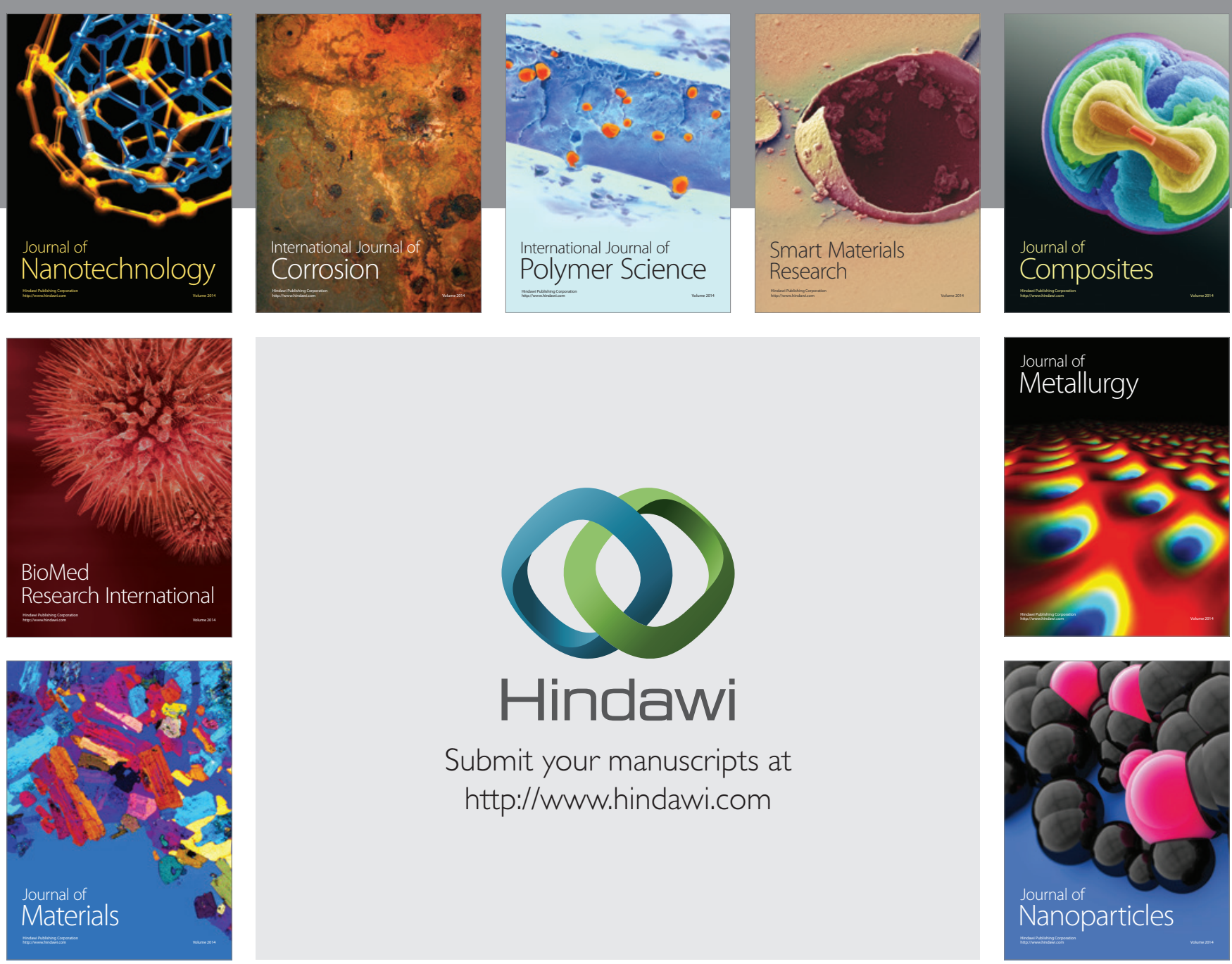

Submit your manuscripts at http://www.hindawi.com
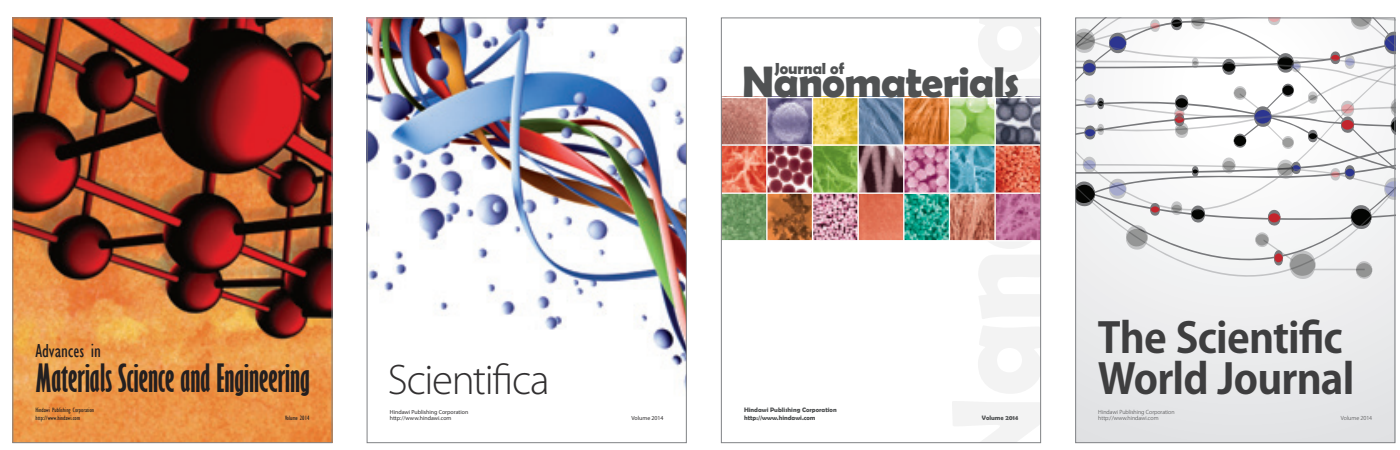

\section{The Scientific World Journal}
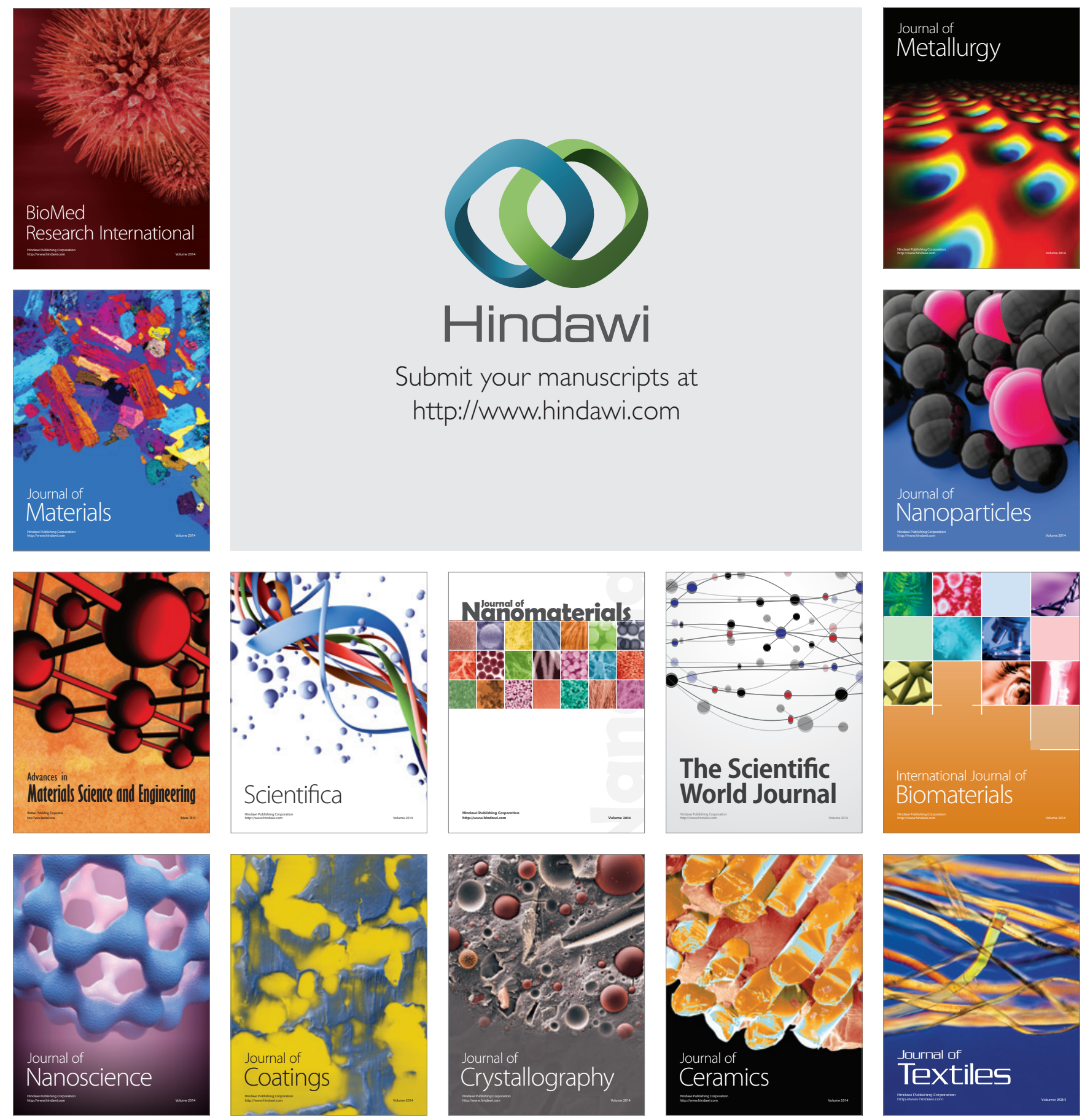